\title{
Response to radiological accidents: the role of the International Atomic Energy Agency
}

\author{
I. TURAI ${ }^{1}$, M. CRICK $^{1}$, C. NOGUEIRA DE OLIVEIRA ${ }^{1}$, \\ P. ORTIZ-LÓPEZ ${ }^{1}$, A. WRIXON ${ }^{1}$
}

(Manuscript received 31 July 2001, accepted 29 August 2001)

ABSTRACT The International Atomic Energy Agency has, under its Statute, specifically defined functions relating to radiation safety, in particular, responsibilities for the development of standards of safety and provision for their application. These functions are fulfilled through the development of a wide range of standards, including those on preparedness and response to nuclear accidents or radiological emergencies. It also devotes considerable effort to assisting countries in applying those standards. In addition, the Agency has responsibilities placed on it by virtue of a number of Conventions, two of which are relevant to nuclear accidents or radiological emergencies: the Convention on Early Notification of a Nuclear Accident (Early Notification Convention) and the Convention on Assistance in the Case of a Nuclear Accident or Radiological Emergency (Assistance Convention). Under the Assistance Convention, assistance may include medical response. This paper provides an overview of the Agency's work regarding emergency preparedness and response, with specific reference to a number of recent events. It also discusses new initiatives regarding the safety and security of radiation sources, which have, as a principal objective, the reduction of the risk of such events.

RÉSUMÉ La réponse aux accidents radiologiques : le rôle de l'Agence internationale de l'énergie atomique.

Dans ses statuts, l'Agence internationale de l'énergie atomique a défini avec précision ses fonctions dans la sûreté radiologique, en particulier ses responsabilités dans l'évolution des normes de sûreté, et la prise des dispositions nécessaires à leur application. Elle réalise ces fonctions en faisant évoluer une large gamme de normes, y compris celles portant sur la préparation à la gestion des accidents nucléaires ou à des urgences radiologiques. Elle consacre aussi un effort considérable à l'assistance aux pays, dans l'application de ces normes. De plus, l'Agence a des responsabilités dans ce dernier domaine, en vertu d'un certain nombre de conventions. Deux d'entre elles relèvent des accidents nucléaires ou des urgences radiologiques : la convention de notification rapide d'un accident nucléaire ( « Early Notification Convention »), et la convention sur l'assistance en cas d'accident nucléaire ou d'urgence radiologique (« Assistance Convention $»$ ). Dans ce dernier cas, l'assistance peut inclure une réponse médicale. Cet article présente une vue d'ensemble du travail de l'Agence concernant l'état d'urgence et la réponse à une urgence ; il fait spécifiquement référence à un certain nombre d'évènements récents. II évoque aussi de nouvelles initiatives concernant la sûreté et la sécurité des sources de rayonnement ; elles ont pour objectif principal de réduire le risque de tels évènements.

\footnotetext{
${ }^{1}$ Radiation Safety Section, Division of Radiation and Waste Safety, Department of Nuclear Safety, International Atomic Energy Agency, 1400 Vienna, Austria.
} 


\section{Introduction}

Radiation sources, utilising either radioactive materials or radiation generators, are used throughout the world for a wide variety of beneficial purposes, in industry, medicine, research, defence and education. The risks posed by these sources and materials vary widely, depending on the activities, the radionuclides, the forms, etc. Unless damaged or leaking, sealed sources present a risk from external radiation exposure only. Damaged or leaking sealed sources as well as unsealed radioactive materials may however lead to contamination of the environment and intake of radioactive materials into the human body.

Until the 1950s, only radionuclides of natural origin, particularly radium-226, were generally available. Since then, radionuclides produced artificially in nuclear facilities and accelerators have become widely available, typically cobalt- 60 , strontium-90, caesium-137 and iridium-192. The risks associated with the use of radioactive materials must be restricted and protected against by the application of appropriate radiation safety standards. Regulatory control has, however, sometimes lagged behind developments in the use of radionuclides.

The risks associated with the planned use of radioactive materials are generally well-known and the relevant safety requirements generally well identified. Nevertheless, accidents can occur during use. In recent years there has been a growing awareness of the potential for such accidents, some accidents having had serious, even fatal, consequences.

More recently still, there has been a growing awareness of the problems associated with radiation sources that for one reason or another are not subject to regulatory control or over which regulatory control has been lost. As the sources may be transported across borders, such problems are not necessarily restricted to the State within which they were originally used. Their subsequent recovery by workers or members of the public unaware of the possible hazards, can give rise to external irradiation or, if tampered with, the possibility of internal exposure. This has also led to serious injury and, in some cases, death. Such sources are commonly referred to as "orphan sources", a term which is taken to cover sources that were never subject to regulatory control or, for one reason or another, have been lost from regulatory control.

The International Atomic Energy Agency, which is part of the United Nations family of organisations, has an important role to play in the prevention of accidents involving radiation sources and in dealing with their consequences should such accidents occur. The purpose of this paper is to provide an overview of the 
Agency's activities in this area, to discuss some recent developments and to indicate areas where further developments in the international arrangements are needed.

\section{Functions of the IAEA}

The Agency was established in 1957 as an independent intergovernmental, science and technology based organisation to serve as the global focal point for nuclear co-operation. Amongst other things, it is expressly required by its Statute to establish or adopt... standards of safety of health and minimisation of danger to life and property..., and to provide for the application of these standards... These functions are of high priority in the Agency, and of particular importance in this regard are the Basic Safety Standards for radiation safety.

The Agency's Board of Governors first approved Basic Safety Standards for radiation protection in June 1962. Three revised editions have been issued since then, in 1967, 1982 and 1996. The latest edition, entitled the International Basic Safety Standards for Protection against Ionising Radiation and for the Safety of Radiation Sources (the BSS) (IAEA, 1996c), was the product of extensive global co-operation. They are based closely on the recommendations of the International Commission on Radiological Protection (ICRP, 1990), and are sponsored by five other organisations ${ }^{2}$ in addition to the Agency. They stipulate the basic requirements for protection and safety and provide the basis for national regulations in a large number of countries. They are also reflected in the regulatory documents of the major international bodies. Other documents have been or are being developed to complement and support the requirements given in the BSS and those relevant to accidents are mentioned below.

The Agency also services a number of Conventions relevant to safety, which are legally binding agreements that have been developed and adopted by the international community. Two are relevant to the matter of radiological accidents, namely the Convention on Early Notification of a Nuclear Accident (IAEA, 1986b) and the Convention on Assistance in the Case of a Nuclear Accident or Radiological Emergency (IAEA, 1986a). Both were developed following the Chernobyl accident in 1986 and entered into force on 27 October 1986 and on 26 February 1987, respectively.

\footnotetext{
${ }^{2}$ Food and Agriculture Organization of the United Nations, Intemational Labour Organization, Nuclear Energy Agency of the Organization for Economic Co-operation and Development, Pan American Health Organization and World Health Organization.
} 


\section{Accidents with ionising radiations}

The BSS (IAEA, 1996c) define an accident as any unintended event, including operating error, equipment failure or other mishap, the consequences or potential consequences of which are not negligible from the point of view of protection or safety. This definition covers both nuclear accidents and radiological emergencies, the latter, being those accidents that occur in general in the manufacture, use, storage, disposal, and transport of radioisotopes or application of radiation generating devices for industrial, medical, agricultural, and related scientific and research purposes. It is not however sufficient for the purposes of determining those accidents that are likely to produce significant medical consequences in the short term. For this, dose criteria have been proposed. A radiation exposure is considered to be significant if at least one person received an effective (whole body) dose exceeding $0.25 \mathrm{~Sv}$, or the absorbed dose by the exposed area of skin is more than $6 \mathrm{~Gy}$, or the dose to any other organ is most probably higher of $0.75 \mathrm{~Gy}$. These dose criteria were proposed by the US Nuclear Regulatory Commission in 1974 and are used by the Radiation Accident Registries of Radiation Emergency Assistance Center and Training Site, Oak Ridge, USA (Ricks, 1999).

Radiological emergencies are fortunately rare. The statistics vary somewhat with author depending on the definition used and the extent of the information available. However, from the information available to the Agency, there has been a total of about 400 such accidents between 1944-June 2001 world wide, with about 3000 persons significantly exposed to radiation, 133 of whom died (Ricks, 1999; IAEA, 1998g). Currently, radiological emergencies with severe exposures and even fatal outcomes appear to be occurring a few times a year.

Radiological accidents can be divided into three broad groups. The first comprises those that occur at work, the most common of which are in industrial radiography and the most serious of which are with industrial irradiators and electron beam accelerators. Accidents in gamma irradiation facilities generally result in fatalities; accidents with radiography sources or electron beam accelerators often result in the amputation of fingers and limbs. The second group comprises accidents involving patients undergoing radiotherapy. These are mainly due to calibration errors, which, if undetected, can have serious consequences for large numbers of patients; both death and severe degradation in the quality of life of the patients have been associated with these accidents. The third group comprises accidents with orphan sources. Depending on their activity and the exposure time, their consequences may either appear in the form of acute local radiation injuries or protracted whole body exposures, occasionally with fatal outcomes. 


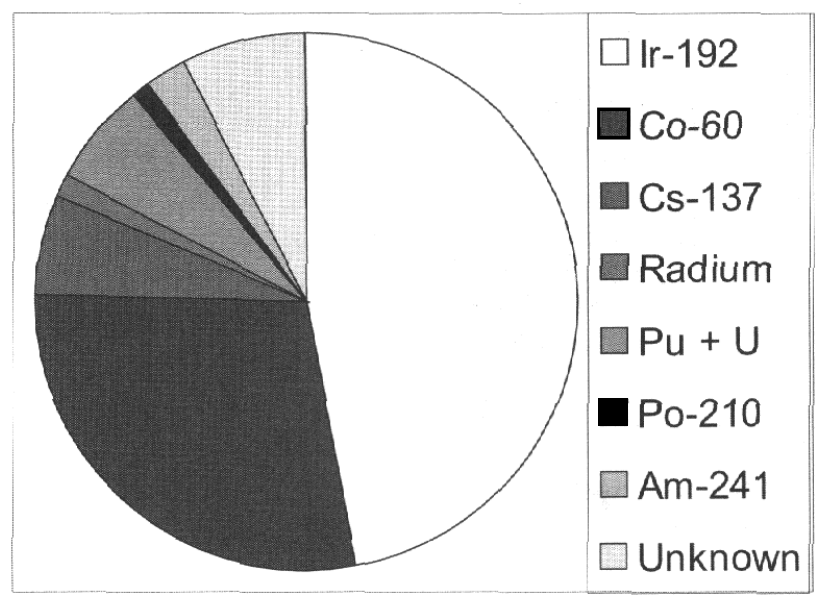

Figure 1 - Radiological accidents by radionuclides, 1945-2000.

Les accidents radiologiques impliquant des radionucléides, 1945-2000.

For a number of years, it has been the practice of the Agency, at the request of the State within which the accident occurred, to undertake a review of the accident. Several of these reviews are already published (IAEA, 1988, 1990, 1993, 1996a, e, 1998a, c, e, f, 2000h, i, j, l); including, reports on the accident in Turkey at the end of 1998 involving a cobalt-60 radiotherapy source, in Peru in 1999 with an iridium-192 industrial radiography and the accident in Georgia in 1997 involving a number of abandoned cobalt- 60 and caesium- 137 sources. The reports on the Thai accident in 2000, which had many similarities with the accident in Turkey, and on the Panamanian accident involving 28 radiotherapy patients in $2000 / 2001$, are in the process of being published. A summary of the major known radiological accidents as of 1999 is provided in reference (González, 1999).

Figures 1 and 2 provide a summary of the accident data available within the Agency. Figure 1 provides a breakdown of the information by radionuclide. What is immediately obvious from this is that iridium- 192 account for about $45 \%$ of the number of accidents; this is undoubtedly due to the extensive use made of this radionuclide in industrial radiography. Figure 2 shows a breakdown by type of use. Almost $50 \%$ of the accidents occur in general industry, again a reflection of the significance of industrial radiography accidents. Only $9 \%$ occur in the medical domain, although these accidents produce about $50 \%$ of the deaths. Only $4 \%$ of the accidents occur in irradiator facilities, although, as already mentioned, many of these accidents result in the death of the exposed person. 

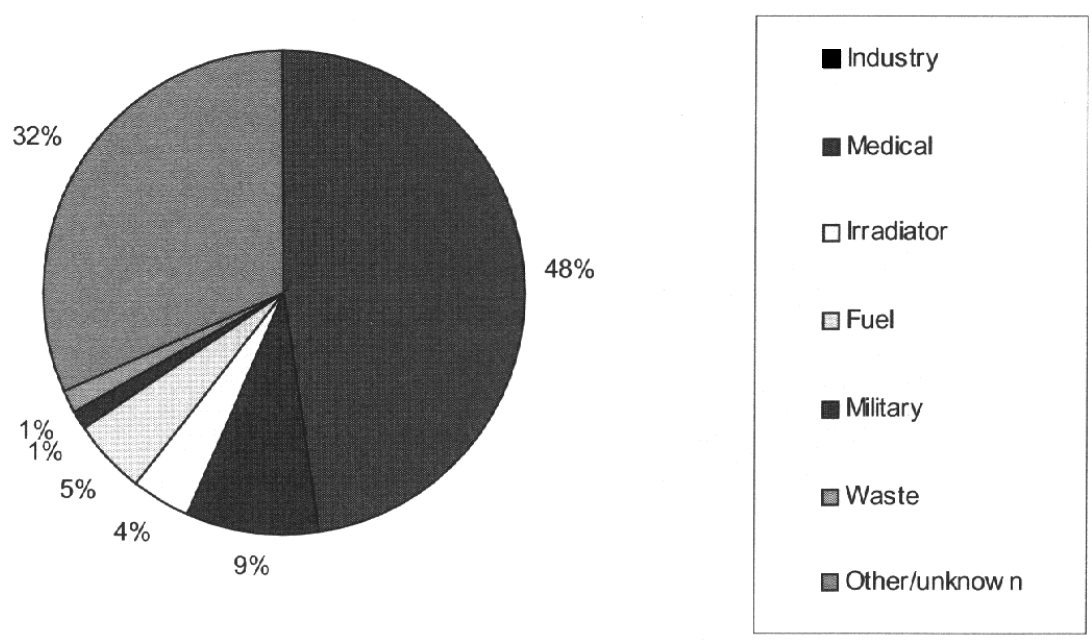

Figure 2 - Radiological accidents by facility type, 1945-2000.

Les accidents radiologiques par types d'installations, 1945-2000.

\section{Conventions}

The Early Notification Convention establishes a notification system for nuclear accidents which have the potential for international transboundary release that could be of radiological safety significance for another State. It requires States to report the accident's time, location, radiation releases, and other data essential for assessing the situation. Notification is to be made to affect States directly or through the Agency, and to the Agency itself. Reporting is mandatory for any nuclear accident involving the facilities and activities listed in the Convention. These include the transport and storage of... radioactive wastes; the manufacture, use, storage and transport of radioisotopes for agricultural, industrial, medical and related scientific and research purposes; and the use of radioisotopes for power generation in space objects. So the scope is much broader than accidents in nuclear installations.

Amongst other things, States Parties to the Convention are required to make known to the Agency and other States Parties, its competent authorities and points of contact responsible for issuing and receiving the notification and other information.

The Assistance Convention sets out an international framework for cooperation among States Parties and with the Agency to facilitate prompt assistance 
and support in the event of nuclear accidents or radiological emergencies. It requires States to notify the Agency of their available experts, equipment, and other materials for providing assistance. In the case of a request, each State Party decides whether it can render the requested assistance as well as its scope and terms. Assistance may be offered without costs to the requesting State taking into account inter alia the needs of developing countries without nuclear facilities. The Agency serves as the focal point for such co-operation by channelling information, supporting efforts, and providing its available services.

Specifically, if a State Party needs assistance, whether or not the accident or emergency originates within its territory, it may call for such assistance from any other State Party, directly or through the Agency, and from the Agency itself, or, where appropriate, from other international intergovernmental organisations. The request may include assistance relating to medical treatment or temporary relocation into the territory of another State Party of people involved in an accident.

Particular responsibilities imposed by the Assistance Convention on the Agency include the following:

- preparation of emergency plans and appropriate legislation;

- development of appropriate training programmes;

- transmission of requests for assistance and relevant information;

- development of appropriate radiation monitoring programmes, procedures and standards;

- conducting investigations into the feasibility of establishing appropriate radiation monitoring systems;

- making available appropriate resources for the purpose of conducting an initial assessment of the accident;

- offering its good offices in the event of an accident;

- establishing and maintaining liaison with relevant international organisations.

A particularly delicate matter is that of the confidentiality of information. Here the Assistance Convention clearly recognises the competing pressures that exist in the modern world - between the desire for openness of information and the need to protect the interests of those involved in the accident. The Convention specifies: the requesting State and the assisting party shall protect the confidentiality of any confidential information that becomes available to either of them in connection with the assistance in the event of a nuclear accident or radiological emergency. Such information shall be used exclusively for the purpose of the assistance agreed upon. The assisting party shall make every effort to co-ordinate with the requesting State before releasing information to the public on the assistance provided in connection with a nuclear or radiological emergency. 


\section{Functions of the Emergency Preparedness and Response Unit}

To cope with its obligations under its statute regarding standards for emergency preparedness and response and under these two Conventions, the Agency has established the Emergency Preparedness and Response Unit (EPRU). This Unit is the focal point in the Agency for all emergency preparedness and response activities. It has a programme of work dedicated to resolving Member States' current deficiencies in emergency preparedness and to ensuring, on a 24 hour basis, the Agency's quick response to a notification of an accident or a request for assistance from a Member State.

The Conventions place specific obligations on the Agency with regard to information management and provision of emergency assistance for serious nuclear accidents, and life-threatening radiological emergencies, which happen very seldom. In order to fulfil these obligations, the Agency has established and maintains an Emergency Response System and, as part of this system, an Emergency Response Centre (ERC) was created.

The primary objectives of the Agency's Emergency Response System are:

- to fulfil all obligations placed on the Agency by the two Conventions;

- to authenticate and verify unsubstantiated reports of nuclear accidents or radiological emergencies and to provide authoritative information to requesting Parties, without undue delay;

- to ensure that Member States' representatives are appropriately briefed on any developing situation;

- to ensure, in co-ordination with other relevant international organisations, that there are frequent, appropriate, accurate and reliable releases of information to the news media;

- to interact with other relevant international or intergovernmental organisations to co-ordinated the international response;

- and to review the response by the Accident State and by the Affected States to identify areas where significant gaps in the response with regard to nuclear and/or radiation safety may exist and, in those cases, to offer the good offices and advice of the Agency.

The Agency's Nuclear Accident/Radiological Emergency Assistance Plan (NAREAP) defines the roles of the Secretariat in responding to an emergency; assigns authorities and responsibilities for making decisions and performing emergency tasks; and describes the concept of operations for emergency response to meet the Agency's obligations (IAEA, 2000g). Staff allocated to specific duties are periodically trained and exercised. 
Since 1989, the arrangements between the Agency, States which are Member States and/or Parties to one or both Conventions, all other international intergovernmental organisations, and other States for facilitating the implementation of the Conventions - specifically of those of their articles which are operational in nature - have been documented in the Emergency Notification and Assistance Technical Operations Manual (ENATOM). This manual is intended for use primarily by the Contact Points, as defined in the Conventions. The latest version of this manual was published in December 2000 (IAEA, 2000b).

An extra resource to the system is foreseen through the Agency's Emergency Response Network (ERNET) (IAEA, 2000c). ERNET will consist of suitably qualified emergency response teams from Member States organised on the basis of regional emergency response capabilities into a global network for a rapid international response in the event of a nuclear accident or radiological emergency. ERNET is designed to respond to specific needs and does not affect the cooperation arrangements defined in any bilateral and/or multilateral agreements between States. Its major purposes are:

(a) to strengthen the Agency's response capability to provide assistance and advice and/or to co-ordinate the provision of assistance as specified within the framework of the Assistance Convention;

(b) and to promote emergency preparedness and response capabilities for nuclear accidents or radiological emergencies among Member States.

The Inter-Agency Committee on the Response to Nuclear Accidents (IACRNA), comprising those international organisations with responsibilities for nuclear or radiological accidents, meets annually in order:

(a) to ensure exchange of information among agencies concerning their respective activities and to ensure the harmonisation of these activities;

(b) to review progress in joint activities;

(c) and to identify new areas for inter-agency co-operation and to plan joint actions.

The Committee has developed a Joint Radiation Emergency Preparedness and Response Plan of the International Organisations (EPR-JPLAN) (IAEA, 2000e). This joint plan defines: the objectives of response; the organisations involved in response; their roles and responsibilities; the interfaces between them and between them and their Member States; the concept of operations; and preparedness arrangements such as emergency exercises. The Agency provides the Secretariat for this committee which is presently composed of representatives from various UN system organisations plus the European Commission and the Nuclear Energy Agency of OECD. 


\section{Recent examples of action under the conventions}

\subsection{Georgia, 1997 to 2000}

The authorities in Georgia first requested assistance in October 1997, when a group of frontier guards undergoing training at a centre in Lilo, near Tbilisi, showed signs of radiation induced skin disease. Eleven servicemen were transferred to specialised hospitals in France, Germany and the Russian Federation. The cause of the exposures was found to be several sources of caesium-137 and cobalt- 60 of various activities, abandoned in a former military barracks following the break-up of the Soviet Union. The investigation report for this accident has been published by the Agency (IAEA, 2000i).

In July 1998, three more abandoned sources with an activity of $50 \mathrm{GBq}$, $3.3 \mathrm{GBq}$ and $0.17 \mathrm{GBq}$ caesium-137 were found in Matkhoji, an agricultural village, about $300 \mathrm{~km}$ west of Tbilisi. At the same time, another site of a former Soviet military base close to Kuthaisi was discovered containing an area contaminated with radium-226. Another military base in the city of Poti, close to the Black Sea, was also found to contain two further radioactive sources buried in a sand floor.

In October 1998, two other powerful sources were discovered in Khaishi, western Georgia. The sources were part of eight thermo-electric generators placed in the region. These generators originally had an activity of anything between 740 and $5550 \mathrm{TBq}$, strontium-90. Since then, four of the generators have been located and are now in safe storage. One was recovered from the bed of the Inguri river, which flows through this region in western Georgia. In June 1999, a cobalt-60 source of around $37 \mathrm{GBq}$ was found buried below a road close to the botanical gardens in Tbilisi and in July 1999, two caesium-137 sources were found in the town of Rustavi, close to Tbilisi.

The assistance provided under the Assistance Convention included the biological dosimetry of the inhabitants of the village of Matkhoji. The biodosimetry was carried out by the Institut de Protection et de Sûreté Nucléaire (IPSN, Paris, France). Out of 113 inhabitants, 16 persons were found to have a higher number of dicentrics than normal, although none exhibited any clinical symptoms relating to radiation exposure; the highest dose to the whole body was estimated to be about $0.3 \mathrm{~Gy}$. Assistance was also provided under the Convention in the search for and recovery of the orphan sources. During May 2000, an aerial survey of selected parts of Georgia was performed with the aim of providing some reassurance to the population; this was done with the support of CEA-France. As a result, a further source was recovered. 


\subsection{Turkey, Peru and Ghana, 1999}

During 1999, the Assistance Convention was invoked on 3 occasions, the investigation reports for two of the accidents having been published by the Agency (IAEA, 2000h, j).

In the first instance, medical assistance was provided to Turkey following an accident in which containers of cobalt- 60 radiotherapy sources were sold to a scrap yard. Attempts were made by the scrap yard owners to dismantle the containers; the consequence was that ten persons were exposed to high levels of radiation and hospitalised. The Agency medical team comprised physicians from France, the UK and the Agency, who fully concurred with the appropriateness of the medical management and treatment of these persons.

Assistance was also provided in the search for one of the sources that was thought to be missing. In addition, the Notification Convention was invoked, when it became apparent that there was a significant possibility that a further source that was thought to be missing might have been transferred to another country in the Mediterranean-Black Sea-Middle East region.

On the second occasion in 1999 when the Assistance Convention was invoked, physicians initially provided medical advice from the USA to a Peruvian worker who inadvertently picked up an iridium-192 industrial radiography source. This worker was subsequently transferred to the Serious Burns Treatment Centre of the Percy Military Hospital at Clamart, France for further medical treatment. His leg was subsequently amputated.

On the third occasion, assistance was provided by the Agency in the recovery of an industrial radiography source (iridium-192) which had become stuck in an exposed position in Ghana. In this instance, no injuries had been caused but there clearly was a significant potential for high radiation doses to be received.

\subsection{Thailand, 2000}

In the first part of 2000, the Assistance Convention was invoked following the radiological accident in Thailand. In February, ten persons were severely exposed to an abandoned radiotherapy source containing $15.5 \mathrm{TBq}$ cobalt- 60 . In this instance, the Thai authorities accepted the offer of medical assistance from Japan through the WHO. Three of the most severely exposed persons died within two months. The investigation report for this accident is in the process of being published. 


\subsection{Panama, 2001}

In May 2001, the Government of Panama invoked the Assistance Convention and requested the assistance of the Agency in responding to an accident involving 28 radiotherapy patients at the National Oncology Institute. These patients had been exposed at about twice the level required for their treatment, the cause being that shielding data had been incorrectly entered into the treatment planning system. At the time of the mission, 8 patients had died, and it appeared that 5 of the deaths were probably attributable to radiation exposure. Of the surviving patients, about three-quarters are expected to develop serious complications, which in some cases may ultimately prove fatal. A full report on this accident has been published (IAEA, 2001c).

\section{Safety standards}

The documents in the Agency's Safety Standards Series are a set of regulatorystyle publications that reflect an international consensus on the principles of radiation protection and safety and their application through regulation. They have a hierarchical structure. Safety Fundamentals provide the basic objectives, concepts and underlying principles. Those principles for radiation protection and safety are set out in the Safety Fundamentals: Radiation Protection and the Safety of Radiation sources (IAEA, 1996d). This document explains the approaches to radiation protection and safety, for persons in senior political or regulatory positions, as well as for persons who make decisions regarding the uses of radiation in medicine, industry, agriculture and other areas.

At a lower level, the Safety Requirements documents provide the basic requirements that must be satisfied to ensure safety for particular activities or application areas. Of prime importance in this category are the BSS (IAEA, $1996 \mathrm{c}$ ), which establish basic requirements for radiation protection and safety, specify obligations and responsibilities and set out the requirements for application to practices and in intervention situations.

The BSS rely on the existence in a State of a system for the notification, registration and licensing of sources and presuppose that governments have the authority and resources to deal with the safety and security of radiation sources and have established independent regulatory authorities to authorise activities involving sources, inspect them, enforce safety requirements and, if necessary, conduct intervention. These aspects are covered in a separate Safety Requirements document (IAEA, 2000f). 
A set of requirements for nuclear and radiological emergency preparedness and response, co-sponsored by relevant international organisations, is currently being developed to provide a harmonised approach across all areas of nuclear, radiation, radioactive waste and transport safety.

Safety Guides provide recommendations, on the basis of international experience, relating to the fulfilment of the requirements. Two Safety Guides are envisaged to support the Safety Requirements on emergency preparedness and response. First, there will be a revision of IAEA Safety Series No. 109 (IAEA, 1994), which deals with criteria for intervention. Second, there will be a document entitled Planning for Response to Nuclear and Radiological Accidents. This will provide detailed guidelines and recommendations for emergency response preparedness for all threats and for all response organisations, including guidelines on determining the level of radiological hazard in a country and developing an adequate and appropriate emergency response capability to meet that threat. An interim version of this document has been issued as an IAEA Technical Document, entitled Method for the Development of Emergency Response Preparedness for Nuclear or Radiological Accidents (IAEA-TECDOC-953) (IAEA, 1997b). A major benefit of this document is that it enables a country to assess its own state of preparedness, promoting responsibility rather than dependence on external assistance.

\section{Provision for the application of standards}

\subsection{Documents}

The Agency's work in providing for the application of its Safety Standards manifests itself in a number of ways. The first is through the publication of documents in support of the standards themselves. Safety Reports provide practical examples and detailed methods that can be used for the application of the Standards. Specifically, on emergency preparedness and response, the Agency intends to issue a set of practical Safety Reports covering various aspects of assessment, monitoring and response. The first of these is Generic Assessment Procedures for Determining Protective Actions during a Reactor Accident. An interim version, published as IAEA-TECDOC-955 (IAEA, 1997a), covers the initial assessment of facility conditions, environmental data and protective action decision making.

A simple but effective computer code for projecting the possible consequences of an accident, particularly a nuclear accident, on the basis of facility conditions and limited environmental data has also been prepared. A TECDOC on Generic Procedures for Monitoring in a Nuclear or Radiological Emergency (IAEA, 1999) 
was published and one on Generic Procedures for Assessment and Response in a Radiological Emergency is to be published. Three other TECDOCs are currently under development, entitled Generic Procedures for Preparation, conduction and Evaluation of Exercises; Generic Procedures for Public Information Management and Generic Procedures for Medical Preparedness and Response. These practical documents are published in English, Russian and Spanish.

One TECDOC deals with the assessment and treatment of external and internal radionuclide contamination (IAEA, 1996b). Two Safety Reports (IAEA, $1998 \mathrm{~b}, \mathrm{~g}$ ), which are cosponsored by WHO, deal with the medical preparedness and medical response to radiological accidents, and the diagnosis and treatment of radiation injuries, respectively.

\subsection{Training programmes}

The specific objective of this activity is to conduct training in the use of the above publications and to assist Member States in the development of their emergency preparedness capabilities. The following are noted.

- Training at the regional and national level. Courses and workshops have been conducted for personnel responsible for the application of the Agency's guidelines on emergency preparedness and response. The participants are shown how to use the documents: (a) to develop an emergency capability that is adequate for their level of threat; (b) to assess facility and environmental data and make plans for protective action for the public and workers in an emergency; and (c) to perform radiation monitoring, environmental sampling and laboratory analysis in response to a nuclear or radiological accident. The material provided should also assist them in conducting national workshops. The strategy throughout is that of train-the-trainers to maximise the number of people trained in specialist subjects.

- Expert missions and assistance. Numerous Technical Co-operation (TC) Projects at the national and regional level have been initiated that provide expert assistance, equipment and training in emergency preparedness. These include the Model Project on Upgrading Radiation Safety Infrastructures in approximately 50 Member States. One of the goals of this project is to ensure that these countries reach an adequate capability to respond to accidents.

- Regional and national training courses on medical preparedness and response to radiological accidents. In 1997-2000, over 500 medical doctors and emergency responders were trained at six regional and ten national training courses organised or assisted by the Agency.

- Standardised training courses. Standardised programmes have been prepared and lecture notes for each course module are currently being developed. 
A IAEA-WHO Leaflet and Poster on "How to recognise and initially respond to an accidental radiation injury" was published in 2000 in each UN language for dissemination to medical doctors (primarily General Practitioners) and medical students (IAEA, 2000d).

\section{New initiatives}

The International Conference on the Safety of Radiation Sources and the Security of Radioactive Materials was held in Dijon, France in September 1998 was the first major meeting on this topic (IAEA, 1998d). The conclusions were reported to the Agency's General Conference, the eventual outcome of that was the establishment, in 1999, of an Action Plan to enable the Agency to assist its Member States in improving the safety and security of radiation sources over their life cycle. The Plan has 7 distinct areas:

- regulatory infrastructures. The Agency has now established a service to advise States on the establishment of appropriate regulatory programmes;

- management of disused sources. Many accidents have been caused by redundant sources left in unsuitable stores, so the Agency has been developing support to help deal with this;

- categorisation of sources. This is necessary so that a graded approach to source management can be applied. The categorisation is now published (IAEA, 2000a);

- response to abnormal events. This involves the strengthening of the Agency's response capabilities and the development of guidance on national strategies for the recovery of control over orphan sources. A Technical Document is currently being developed to provide appropriate guidance on national strategies;

- information exchange. Through workshops and conferences, the Agency hopes to increase awareness of the issues. A Conference was held in Buenos Aires in December 2000. This area also includes the development of a database on unusual events (RADEV) and the dissemination of information on sources;

- education and training. This is fundamental to safety and a more structured approach is being developed by the Agency in this area;

- international undertaking. The purpose of this is to reinforce the resolve of States to the regulatory control of sources. A Code of Conduct has now been published (LAEA, 2001a).

The conclusions of the Conference in Buenos Aires were reported to the Board of Governors in March 2001 and, as a result, the Action Plan has been updated. Recommendations for further action were, in summary:

- consider the development of a hazard warning label that immediately warn the uninitiated; 
- establish at the time of purchase the duty of suppliers to take back sources;

- governments should ensure that arrangements are made between authorities and scrap-yard operators regarding the detection and future handling of orphan sources;

- clearly distinguish security breaches that are without malice aforethought from those with criminal intent - this has implications regarding border monitoring.

There was also emphasis on the need for States to develop their own national strategies for recovery of control over orphan sources.

\section{Conclusions}

Radiological accidents are relatively rare; experience shows that on average a few severe accidents involving death or serious deterministic effects to individuals can be expected each year. Such accidents occur in both developed and developing countries, but clearly are more likely in those countries where strict controls are lacking. Since virtually all countries use radiation sources in some form or other, particularly for medical, but also for industrial purposes, and the use of radiation sources is likely to grow, the number of serious radiological accidents can be expected to increase if such strict controls are not in place and maintained. The Agency for its part is taking this matter seriously and has a number of programmes in place to assist countries. These include the development of appropriate safety standards relating to the control of sources, regulatory infrastructures and the preparedness and response to nuclear accidents or radiological emergencies and the operation of the IAEA's Emergency Response Centre to service the two relevant international conventions. The matter has been given further emphasis by the development of an Action Plan specifically directed at the control of radiation sources, from cradle to grave.

\section{REFERENCES}

González A. (1999) Strengthening the Safety of Radiation Sources and the Security of Radioactive Materials, Timely Action, IAEA Bull. 41 (3).

IAEA (1986a) Convention on Assistance. in the Case of a Nuclear Accident or Radiological Emergency, Vienna, Austria.

IAEA (1986b) Convention on Early Notification of a Nuclear Accident, Vienna, Austria.

IAEA (1988) The Radiological Accident in Goiânia, Vienna, Austria.

LAEA (1990) The Radiological Accident in San Salvador, Vienna, Austria.

IAEA (1993) The Radiological Accident in Soreq, Vienna, Austria.

IAEA (1994) Intervention Criteria in a Nuclear or Radiation Emergency, Safety Series No. 109, Vienna, Austria.

IAEA (1996a) An Electron Accelerator Accident in Hanoi, Viet Nam, Vienna, Austria.

IAEA (1996b) Assessment and Treatment of External and Internal Radionuclide Contamination, IAEA-TECDOC-869, Vienna, Austria. 


\section{RESPONSE TO RADIOLOGICAL ACCIDENTS}

IAEA (1996c) International Basic Safety Standards for Protection against Ionizing Radiation and for the Safety of Radiation Sources, Safety Series No. 115, Vienna, Austria.

IAEA (1996d) Radiation Protection and the Safety of Radiation Sources, Safety Series No. 120, Vienna, Austria.

IAEA (1996e) The Radiological Accident at the Irradiation Facility in Nesvizh, Vienna, Austria.

IAEA (1997a) Generic Assessment Procedures for Determining Protective Actions during a Reactor Accident, LAEA-TECDOC-955, Vienna, Austria.

IAEA (1997b) Method for the Development of Emergency Response Preparedness for Nuclear or Radiological Accidents, IAEA-TECDOC-953, Vienna, Austria.

IAEA (1998a) Accidental Overexposure of Radiotherapy Patients in San José, Costa Rica, Vienna, Austria.

IAEA (1998b) Diagnosis and Treatment of Radiation Injuries, Safety Report No. 2, Vienna, Austria.

IAEA (1998c) Dosimetric and Medical Aspects of the Radiological Accident in Goiania in 1987, IAEA-TECDOC-1009, Vienna, Austria.

IAEA (1998d) Safety of Radiation Sources and Security of Radioactive Materials, Proceedings of a conference, Dijon, France, September 1998.

IAEA (1998e) The Radiological Accident in Tammiku, Vienna, Austria.

IAEA (1998f) The Radiological Accident in the Reprocessing Plant at Tomsk, Vienna, Austria.

IAEA (1998g), Planning the Medical Response to Radiological Accidents, Safety Reports Series No. 4, Vienna, Austria.

IAEA (1999) Generic Procedures for Monitoring in a Nuclear or Radiological Emergency, LAEATECDOC-1092, Vienna, Austria.

IAEA (2000a) Categorization of Radiation Sources, IAEA-TECDOC-1191, Vienna, Austria.

IAEA (2000b) Emergency Notification and Assistance Technical Operations Manual (ENATOM), Vienna, Austria.

IAEA (2000c) Emergency Response Network (ERNET), Vienna, Austria.

IAEA (2000d) How to recognize and initially respond to an accidental radiation injury, Leaflet and Poster, Vienna, Austria.

IAEA (2000e) Joint Radiation Emergency Management Plan of the International Organizations (EPRJPLAN), Vienna, Austria.

IAEA (2000f) Legal and Governmental Infrastructure for Nuclear, Radiation, Radioactive Waste and Transport Safety, Safety Standards Series No. GS-R-1, Vienna, Austria.

IAEA (2000g) Nuclear Accident/Radiological Emergency Assistance Plan (NAREAP), Vienna, Austria.

IAEA (2000h) The Radiological Accident in Istanbul, Vienna, Austria.

IAEA (2000i) The Radiological Accident in Lilo, Vienna, Austria.

IAEA (2000j) The Radiological Accident in Yanango, Vienna, Austria.

IAEA (2001a) Code of Conduct on the Safery and Security of Radioactive Sources, IAEA/CODEOC/2001, Vienna, Austria.

IAEA (2001b) The Criticality Accident in Sarov, Vienna, Austria.

IAEA (2001c) Investigation of an Accidental Exposure of Radiotherapy Patients in Panama, Vienna, Austria

ICRP Publication 60 (1990) Recommendations of the International Commission on Radiological Protection, Ann. ICRP 21 (1-3).

Ricks R. (1999) REAC/TS Registry of Radiation Accidents, 1944-1999, REAC/TS, Oak Ridge. 